confidence with RCPCH question style. In addition, openended questions sought to identify problems with the teaching programme and barriers to attendance.

Results All trainees reported improved confidence in their ability pass their exams and answer MCQ style questions. Trainee confidence in passing the FOP/TAS exam improved from $51.8 \%$ pre-course to $87.2 \%$ post course. Trainee confidence in answering $\mathrm{RCPCH}$ exam style questions improved from $48.2 \%$ pre-course to $100 \%$ post course.

Areas identified as requiring course improvement included:

- Teaching style: non-interactive power point, limited MCQ practice

- Course timing: trainee exhaustion from 4-day course run consecutively

- Funding: reliance on sponsored lunches.

Discussion Over the last 6-years, by analysing trainee feedback and working together with the head of school, we have been able to develop a unique course, which provide a high-quality teaching to prepare trainees for their FOP/TAS examinations. One of the key contributors to our success was changing the course teaching style. Power points were replaced by interactive one-hour cased based discussions, paired with best of five and extending matching questions. Problems with accessibility were addressed by holding the course immediately prior to the trainees starting their training programme. This maximised trainee attendance rates as it has avoided the needed for study leave applications. Furthermore, breaking the four-day course up by running it either side of a weekend has ensured trainees are energised and productive. Sponsored lunches required trainees to engage in presentations during their breaks. The top slicing of the study leave budget has allowed us to provide food and drink, giving the trainees a much-needed rest.

\section{G97(P) A QI PROJECT TO INTRODUCE POINT OF CARE CRP TESTING FOR ASYMPTOMATIC BABIES RECEIVING ANTIBIOTICS ON THE POST NATAL WARD}

E Dyer, K Styles, N Bartrum, M Radomska. Evelina London Children's Hospital, London, UK

\subsection{6/archdischild-2020-rcpch.78}

Aim To see if point-of-care (POC) rather than laboratory Creactive protein (CRP) testing on the postnatal ward (PNW) leads to earlier discharge for asymptomatic babies $>37$ weeks gestation who have been screened and treated for sepsis based on risk factors alone.

Method Babies > 37 weeks gestation receiving antibiotics for sepsis risk factors on the PNW were prospectively identified from the daily medical handover list. The trust sepsis risk factors are maternal group B streptococcal infection, prolonged rupture of membranes $>18$ hours and suspected maternal sepsis. Babies were excluded if clinically unwell. In our trust all babies meeting the threshold for screening and treating for infection have a full blood count, CRP and blood culture at birth with antibiotics administered afterwards. A second CRP should be performed at 18-24 hours of life. Babies who remain clinically well with the second CRP being $<10$, will stop antibiotics prior to the 48-hour blood culture result and be discharged back to midwifery care. We investigated whether these babies had their second CRP performed at the correct time and if they were discharged earlier with using the POC CRP testing.
Results

\begin{tabular}{lll}
\hline & $\begin{array}{l}\text { Cohort 1- laboratory } \\
\text { 2nd CRP }\end{array}$ & $\begin{array}{l}\text { Cohort 2- POC } \\
\text { 2nd CRP }\end{array}$ \\
\hline $\begin{array}{l}\text { Number of babies } \\
\text { Most common reasons for antibiotics }\end{array}$ & $\begin{array}{l}\text { Maternal pyrexia/ } \\
\text { sepsis }\end{array}$ & $\begin{array}{l}19 \\
\text { Maternal pyrexia/ } \\
\text { sepsis } \\
\text { Prolonged rupture } \\
\text { membranes }\end{array}$ \\
$\begin{array}{l}\text { Birth CRP<1 } \\
\begin{array}{l}\text { Average length of time (hours) between } \\
\text { 1st and 2nd CRP (target 18-24) }\end{array}\end{array}$ & 25 & $100 \%$ \\
$\begin{array}{l}\text { \% with 2nd CRP<10, suitable to have } \\
\text { antibiotics stopped }\end{array}$ & $63 \%$ & 24 \\
$\begin{array}{l}\text { Average time taken to stop antibiotics } \\
\text { after CRP result (hours) }\end{array}$ & 8 & $53 \%$ \\
$\begin{array}{l}\text { Total number unnecessary antibiotic doses } \\
\text { given }\end{array}$ & 8 & 5 \\
$\begin{array}{l}\text { Average time of discharge to midwifery } \\
\text { care after 2nd CRP result (hours) }\end{array}$ & 16 & 5 \\
\hline
\end{tabular}

Conclusion Babies receiving POC CRP testing on the PNW had their antibiotics stopped slightly sooner and were discharged to midwifery care slightly earlier, however these differences were slight. They did not go home sooner as many required further midwifery care, most commonly feeding support. We anticipate that as our teams become more familiar with the POC CRP testing less babies will receive unnecessary doses of antibiotics and will return to midwifery care sooner.

\section{G98(P) ABSTRACT WITHDRAWN}

\section{G100(P) HOW DO WE ENCOURAGE A CHANGE OF BEHAVIOUR AROUND COLLEAGUES TAKING BREAKS?}

A Baverstock, L Stewart, C White. Wellbeing and Improvement Team, Musgrove Park Hospital, Taunton, UK, Paediatric Department, Salisbury NHS FT, Salisbury, UK

\subsection{6/archdischild-2020-rcpch.79}

We relaunched our HALT (are you Hungry, Angry, Late or Tired?) campaign with poster and enhanced communications. To change behaviour around break culture more was needed.

Aim To increase colleague wellbeing by improving the percentage of colleagues taking a break.

Methods As part of our wellbeing conference we ran a HALT workshop. Including some background information around the positive benefits of taking a break, barriers and enablers to taking a break. We captured baseline data at beginning of the conference and collected post conference data. Ongoing data collection to see if changes have been sustained.

Results 91 colleagues attended our workshop. We asked on a Likert style scale how energised they felt from low - high to 9 low energy levels. At the beginning of the shift 3/9 (range 1-7) and at the end 5/9 (Range 1-9).

Barriers and enablers to taking a break were at organisation, team and individual level. Enviromental factors included 'no staff room', 'always connected to technology'. Workload 


\begin{tabular}{lllll}
$\begin{array}{l}\text { Abstract G100(P) Table } 1 \\
\text { breaks? }\end{array}$ & How regularly are you taking your \\
\hline & $\begin{array}{l}\text { Pre- } \\
\text { Conference }\end{array}$ & $\begin{array}{l}\text { Post } \\
\text { Conference }\end{array}$ & $\begin{array}{l}\text { July } \\
2019\end{array}$ & $\begin{array}{l}\text { October } \\
2019\end{array}$ \\
\hline & $44 \%$ & $87 \%$ & $59 \%$ & TBC \\
\hline $\begin{array}{l}\text { Always/Mostly Taking a Break } \\
\text { Sometimes/Occasionally/Never }\end{array}$ & $56 \%$ & $13 \%$ & $41 \%$ & TBC \\
\begin{tabular}{l} 
Taking a Break \\
\hline
\end{tabular} & & & & \\
\hline
\end{tabular}

pressure was also an issue 'the squeeze'. 'Unexpected work' and 'lack of wiggle room' alongside 'staffing shortages' made planning difficult. 'Peer pressure' to keep working and 'not being seen as a human being' with a sense of 'personal guilt' need to be addressed.

Environment: 'nice staff room' and 'ability to hand bleep over' with 'scheduling breaks as a team'. Leaders also need to role model alongside 'giving yourself permission'. We all need to find 'courage to have break uninterrupted'.

Discussion Our workshop shows there are barriers and enablers to taking a break. Changes are needed as individuals but more importantly as teams and organisations to enable all colleagues to feel empowered to take their breaks. Our workshop has shown an improvement in number of colleagues taking a break. We are now planning the next stage to roll out wider.

\section{G101(P) TEAM EQUIP (EDUCATION IN QUALITY IMPROVEMENT IN PAEDIATRICS)}

SJ Gray.

\subsection{6/archdischild-2020-rcpch.80}

\section{Background}

- No previous team-based multi-disciplinary Quality Improvement (QI) training package in child health in region

- Huge appetite for change across city/trust - bid made to Health Education England

\section{Aim}

- To deliver a 1-year QI programme to groups of multidisciplinary professionals working across child health in city and facilitate group project work-streams (minimum of 8) utilising these QI skills to deliver specific, measurable, achievable, realistic improvements within the year.

Process

- All groups working with children invited across hospital trust \& primary care

- 15 Team EQUIP sessions organised with standardised structure

- First part: Introduction to QI and methodology

- Second part: Interactive project planning (brainstorming areas for improvement, dot voting \& Pareto charting to decide on project(s) followed by driver diagram, process mapping, generating SMART aim \& initial stage planning)

\section{Outcome Measures}

- Pre- and post-course questionnaire relating to knowledge, interest and involvement in QI

- Variable measures for different work-streams

\section{Results}

- 64 attended sessions with improvement in knowledge, interest and likelihood to get involved
- 19 work-streams in progress spanning a wide array of improvement areas relating to child health

\section{Learning Points}

- Running a programme like this single-handedly is massively time consuming but good for quality control

- NHS work pressures are over-whelming (2 sessions cancelled last minute by day surgery and one of the GP teams)

- Incentives (free lunch, prizes, conference funding) work

- Facilitating self-directed projects works wonders for engagement $\&$ motivation for the vast majority (but not all!)

Next Steps

- Supporting ongoing projects \& dissemination via poster production, conference presentations \& publication

- Spread learning \& experience to other specialties through trust-wide QI steering group \& for child health regionally via regional QI network, Q network \& nationally through $\mathrm{RCPCH}$ conference \& RCPCH QI Central

\section{G103(P) QUALITY IMPROVEMENT PROJECT ON HANDOVER SESSIONS IN THE PAEDIATRIC DEPARTMENT OF A DISTRICT GENERAL HOSPITAL}

C Orazulume, L MacKinnon. Paediatrics, Peterborough City Hospital, Peterborough, UK

\subsection{6/archdischild-2020-rcpch.81}

Aims The aims of this project were to improve the quality of morning handover, making them succinct but effective and ensuring they provided learning opportunities for trainees.

Methods We handed out questionnaires to staff in the paediatric department, at random, to conduct a survey. The questionnaire comprised of 11 positive statements about the handover, which they had to qualify as either 'strongly disagree', 'disagree', 'neither agree or disagree', 'agree', 'strongly agree' or 'don't know'. In the first phase (pre-intervention) we gathered their initial responses to these statements. We then introduced our 7-step handover guide (adapted from the $\mathrm{RCPCH}$ handover assessment tool), which was used at every morning handover for 1 month. The staff's opinions on these statements were then re-evaluated using the same questionnaire (postintervention phase).

Results The percentage of staff who answered 'agree' or 'strongly agree' increased after the intervention for 9 out of the 11 positive statements about handover. It was only 'clarity about the most unwell patients at the end of handover' and 'handovers are enjoyable and non-intimidating' that yielded worse results after the intervention.

\section{Questionnaire statements:}

1. The handovers are well structured

2. I feel well-informed about the patients at the end of the handover

3. It is clear who the most unwell patients are at the end of handover

4. I am aware of all the patients with safe-guarding or child protection issues by the end of handover

5. Patients with similar names are clearly identified

6. Important safety issues are highlighted during handover e.g. patients with severe allergies, equipment issues etc.

7. Infection control issues are identified e.g. patients with RSV

8. It is clear which staff are rostered on for the day and whether there are rota gaps 